\title{
Impact of KVK trainings in adoption of home science technologies
}

\author{
ROOPA T. MALABASARI AND UMA S. HIREMATH
}

Received: 09.08.2016; Revised: 11.10.2016; Accepted: 26.10.2016

See end of the paper for authors' affiliations ROOPA T. MALABASARI

Department of Extension and

Communication Management, College of Rural Home Sciences, University of Agricultural Sciences, DHARWAD

(KARNATAKA) INDIA

Email : roopa2chinnu@gmail.com
ABSTRACT : A study was conducted to find out the effectiveness of training programmes on adoption of selected home science technologies imparted by KVK Bagalkot. Total 254 rural women were selected for the study. The data revealed that majority of trained women belonged to high level of adoption in washing powder and phenyl making, maize products, bakery products and medium level in mango products. Dairy management technology adopted by more number of trained women whereas low adoption was found in seed treatment and integrated farming system technology. None of the trained women adopted vermicomposting technology. Size of land holding exhibited significant but negative relationship with respect to adoption level of home science technologies. Major constraints faced by trained women in adoption of the technologies were financial assistance, non-availability of raw materials, market facility, non co-operation and lack of family encouragement.

KEY WORDS: Adoption, Home science technology, Impact, KVK, Rural women, Training

- HOW TO CITE THIS PAPER : Malabasari, Roopa T. and Hiremath, Uma S. (2016). Impact of KVK trainings in adoption of home science technologies. Asian J. Home Sci., 11 (2) : 367-372, DOI: 10.15740/ HAS/AJHS/11.2/367-372. 